\title{
Optimizing preoxygenation prior to tracheal intubation
}

\author{
W. John Russell, PhD
}

Received: 30 July 2009/Accepted: 27 August 2009/Published online: 6 October 2009

(c) Canadian Anesthesiologists' Society 2009

\section{To the Editor,}

The continuing professional development article by Drs. Tanoubi, Drolet, and Donati regarding optimizing preoxygenation addresses a very important aspect of anesthesia. ${ }^{1}$

Unfortunately, their explanation of the related respiratory physiology overlooks one important point. The alveolar fraction of oxygen is diluted not only by the alveolar $\mathrm{CO}_{2}$ but also by the saturated water vapor. Even with complete denitrogenation, there is about an $87 \mathrm{mmHg}$ dilution $\left(\mathrm{PaCO}_{2}\right.$ $40 \mathrm{mmHg}$ and saturated water vapor pressure $47 \mathrm{mmHg}$ at $37^{\circ} \mathrm{C}$ ). Thus, even ideally, the end-tidal $\mathrm{O}_{2}$ is not more than about $89 \%$.

Competing interests None declared.

\section{Reference}

1. Tanoubi I, Drolet P, Donati F. Optimizing preoxygenation in adults. Can J Anesth 2009; 56: 449-66.

\section{Reply}

We sincerely thank Professor Russell for his interesting comment regarding our recent publication. ${ }^{1}$ We agree that alveolar gas is saturated with water vapor, which occupies approximately $6 \%$ of its volume, and that this phenomenon also occurs during preoxygenation. Therefore, with a carbon dioxide fraction of 5\%, the theoretical limit for

W. J. Russell, PhD ( $\square)$

Royal Adelaide Hospital, Adelaide, SA, Australia

e-mail: john.russel@adelaide.edu.au end-tidal oxygen fraction $\left(\mathrm{EtO}_{2}\right)$ is $89 \%$. This has two consequences. First, the volume of oxygen reserves calculated in our article should be decreased by $6 \%,{ }^{1}$ and the estimated apnea times without desaturation should be reduced accordingly. However, the impact of this correction is relatively minor considering that the values quoted for functional residual capacity are approximations with wide interindividual variations.

The second consequence has to do with the target oxygen fraction for adequate preoxygenation. Although the maximum value for $\mathrm{EtO}_{2}$ is $89 \%$ if vapor pressure is taken into account, values $>90 \%$ and, in some cases, $>95 \%$ have been reported in various clinical settings. ${ }^{2-4}$ This has prompted recommendations that $\mathrm{EtO}_{2}$ values $>90 \%$ should be sought to assure optimal preoxygenation. These high values can be explained by what happens to alveolar gas before being analyzed. First, its temperature decreases when it reaches the face mask, circuit, and sample tubing, leading to condensation of water droplets and a reduction in water vapor content. At $22^{\circ} \mathrm{C}$, water vapor pressure is $20 \mathrm{mmHg}$, and it cannot account for more than $2.6 \%$ of the total mixture. Also, gas analyzers are prone to malfunction in the presence of moisture, so they are supplied with devices, such as water traps, desiccators, and/or cooling systems designed to remove as much water as possible. In the end, the gas mixture that is analyzed is essentially dry allowing expired $\mathrm{O}_{2}$ fractions well above $90 \%$. The effect of water vapor pressure on $\mathrm{EtO}_{2}$ measurements was not discussed in any of the articles that we reviewed. We suggest that authors of future studies should describe how water vapor influences the performance of the analyzer they use as part of a rigorous approach to the problem. A similar $\mathrm{plea}^{5}$ was made in the past for accurate measurement of expired $\mathrm{CO}_{2}$ partial pressure. 
Competing interests None declared.

\section{References}

1. Tanoubi I, Drolet $P$, Donati $F$. Optimizing preoxygenation in adults. Can J Anesth 2009; 56: 449-66.

2. Delay JM, Sebbane M, Jung B, et al. The effectiveness of noninvasive positive pressure ventilation to enhance preoxygenation in morbidly obese patients: a randomized controlled study. Anesth Analg 2008; 107: 1707-13.

3. Berry CB, Myles PS. Preoxygenation in healthy volunteers: a graph of oxygen "washin" using end-tidal oxygraphy. $\mathrm{Br} \mathrm{J}$ Anaesth 1994; 72: 116-8.
4. Campbell IT, Beatty PC. Monitoring preoxygenation. Br J Anaesth 1994; 72: 3-4.

5. Severinghaus JW. Water vapor calibration errors in some capnometers: respiratory conventions misunderstood by manufacturers? Anesthesiology 1989; 70: 996-8.

Issam Tanoubi, MD

Pierre Drolet, MD

François Donati, MD, PhD

Hôpital Maisonneuve-Rosemont and Université de Montréal, Montreal, Canada 